\title{
Expanded autologous regulatory T-lymphocyte infusions in ALS
}

A phase I, first-in-human study

Jason R. Thonhoff, MD, PhD, * David R. Beers, PhD, * Weihua Zhao, MD, PhD, Milvia Pleitez, MD, Ericka P. Simpson, MD, James D. Berry, MD, Merit E. Cudkowicz, MD, and Stanley H. Appel, MD

Neurol Neuroimmunol Neuroinflamm 2018;5:e465. doi:10.1212/NXI.0000000000000465

\section{Abstract}

\section{Objective}

To determine whether autologous infusions of expanded regulatory $\mathrm{T}$ lymphoctyes (Tregs) into patients with amyotrophic lateral sclerosis (ALS) are safe and tolerable during early and later stages of disease.

\section{Methods}

Three patients with ALS, with no family history of ALS, were selected based on their differing sites of disease onset and rates of progression. Patients underwent leukapheresis, and Tregs were subsequently isolated and expanded ex vivo. Tregs $\left(1 \times 10^{6}\right.$ cells $\left./ \mathrm{kg}\right)$ were administered IV at early stages ( 4 doses over 2 months) and later stages ( 4 doses over 4 months) of disease. Concomitant interleukin-2 $\left(2 \times 10^{5} \mathrm{IU} / \mathrm{m}^{2} /\right.$ injection $)$ was administered subcutaneously 3 times weekly over the entire study period. Patients were closely monitored for adverse effects and changes in disease progression rates. Treg numbers and suppressive function were assayed during and following each round of Treg infusions.

\section{Results}

Infusions of Tregs were safe and well tolerated in all patients. Treg numbers and suppressive function increased after each infusion. The infusions slowed progression rates during early and later stages of disease. Spearman correlation analyses showed that increased Treg suppressive function correlated with slowing of disease progression per the Appel ALS scale for each patient: patient 1: $\rho$ (rho $)=-0.60, p=0.003$; patient 2: $\rho=-0.71, p=0.0026$; and patient $3: \rho=$ $-0.54, p=0.016$. Measures of maximal inspiratory pressure also stabilized, particularly in 2 patients, during Treg infusions.

\section{Conclusions}

These results demonstrate the safety and potential benefit of expanded autologous Treg infusions, warranting further clinical trials in patients with ALS. The correlation between Treg suppressive function and disease progression underscores the significance of using Treg suppressive function as an indicator of clinical status.

\section{Classification of evidence}

This study provides Class IV evidence. This is a phase I trial with no controls.

\author{
Correspondence \\ Dr. Appel \\ sappel@houstonmethodist.org
}

\section{MORE ONLINE}

$\rightarrow$ Class of Evidence

Criteria for rating

therapeutic and diagnostic

studies

NPub.org/coe

\footnotetext{
*These authors contributed equally to the manuscript.

From the Houston Methodist Neurological Institute (J.R.T., D.R.B., W.Z., M.P., E.P.S., S.H.A.), Houston Methodist Hospital Research Institute, Stanley H. Appel Department of Neurology, Houston, TX; and Neurological Clinical Research Institute (J.D.B., M.E.C.), Massachusetts General Hospital, Boston, MA.

Funding information and disclosures are provided at the end of the article. Full disclosure form information provided by the authors is available with the full text of this article at Neurology.org/NN.

The Article Processing Charge was funded by Department of Neurology, Houston Methodist Hospital.

This is an open access article distributed under the terms of the Creative Commons Attribution-NonCommercial-NoDerivatives License 4.0 (CC BY-NC-ND), which permits downloading and sharing the work provided it is properly cited. The work cannot be changed in any way or used commercially without permission from the journal.
} 


\section{Glossary}

AALS = Appel Amyotrophic Lateral Sclerosis Rating Scale; ALS = amyotrophic lateral sclerosis; ALSA = Amyotrophic Lateral Sclerosis Association; ALSFRS-R = Revised Amyotrophic Lateral Sclerosis Functional Rating Scale; FVC = forced vital capacity; $\mathrm{IL}=$ interleukin; MDA = Muscular Dystrophy Association; MIP = maximal inspiratory pressure.

$\mathrm{CD} 4{ }^{+} \mathrm{CD} 25^{+} \mathrm{FOXP} 3^{+}$regulatory $\mathrm{T}$ lymphocytes (Tregs) are a subpopulation of $\mathrm{T}$ lymphocytes that are immunosuppressive and maintain tolerance to self-antigens, with their dysfunction playing a pivotal role in the development of autoimmune disorders. ${ }^{1-4}$ In amyotrophic lateral sclerosis (ALS) mice, infusions of Tregs slow disease progression and prolong survival, and Tregs suppress the proliferation of responder $\mathrm{T}$ lymphocytes and the activation of microglia. ${ }^{5,6} \mathrm{In}$ patients with ALS, the expression of the Treg master transcription factor FOXP3 is reduced in rapidly progressing patients, ${ }^{7}$ with subsequent impairment of Treg suppressive functions; FOXP3 expression and Treg suppressive functions correlate with the extent and rapidity of disease progression. ${ }^{8}$ When expanded ex vivo in the presence of interleukin (IL)-2 and rapamycin, Treg suppressive function is restored. 8 These data suggest that infusions of expanded autologous Tregs will improve Treg suppressive function in vivo and slow rates of disease progression in patients with ALS. To test these hypotheses, a first-in-human phase 1 study was initiated to determine whether infusions of expanded autologous Tregs into patients with ALS were safe and tolerable during early and later stages of disease. IL-2 was administered concomitantly in the patients in an effort to stabilize and possibly enhance the suppressive functions of the infused Tregs. Furthermore, the relationship between ex vivo Treg suppressive functions and patients' clinical statuses was explored.

\section{Methods}

\section{Primary research question}

Are infusions of expanded autologous Tregs safe and tolerable in patients with ALS during both early and later stages of disease? This study is a phase 1 trial with no controls and provides Class IV evidence that infusions of expanded autologous Tregs are safe and tolerable during early and later stages of disease.

\section{Standard protocol approvals, registrations, and patient consents}

Approval from the Food and Drug Administration and Institutional Review Board at Houston Methodist Hospital was obtained before study initiation. Written informed consent was obtained before enrollment. The study was registered on clinicaltrials.gov (NCT03241784).

\section{Study design and patient selection criteria}

This study was conducted at the Houston Methodist Neurological Institute. Patients with no family history of
ALS, and with differing sites of symptom onset and rates of disease progression, were recruited from Houston Methodist Hospital's Muscular Dystrophy Association (MDA)/ Amyotrophic Lateral Sclerosis Association (ALSA) ALS clinic. Three patients with arm, bulbar, and leg-onset ALS, respectively, were enrolled in the trial (table). Patients were recruited, treated, and followed up between January 2016 and February 2018.

The patients underwent a total of 8 infusions of expanded autologous Tregs with concomitant subcutaneous IL-2 injections. Four Treg infusions were administered every 2 weeks at an early stage of the disease, followed by 4 Treg infusions administered every 4 weeks at a later stage. Each Treg dose was $1 \times 10^{6}$ cells $/ \mathrm{kg}$. The Treg dose was empirically determined but was selected within the range of what has been shown to be safe and tolerable in patients with type 1 diabetes. ${ }^{4}$ IL-2 was administered subcutaneously 3 times weekly at a dose of $2 \times 10^{5} \mathrm{IU} / \mathrm{m}^{2} /$ injection beginning the day after the first Treg infusion and continued throughout the study period.

\section{Infusions of expanded autologous Tregs}

Leukapheresis was performed 1 month before the first Treg infusion. Tregs were isolated and expanded ex vivo in the Good Manufacturing Practice-compliant facility at M.D. Anderson Cancer Center according to a previously described protocol. ${ }^{8,9}$ Each Treg infusion was administered IV through a peripheral line, and patients were closely monitored for any infusion-related adverse responses for 4 hours after the infusion.

\section{Clinical evaluations}

The revised ALS Functional Rating Scale (ALSFRS-R), Appel ALS Rating Scale (AALS), ${ }^{10}$ and maximal inspiratory pressure (MIP) measurements were performed immediately before each Treg infusion, every 2 weeks during each round of infusions, and monthly after each round. Forced vital capacity (FVC) was monitored at each evaluation as a component of the AALS. Patients were asked about adverse events at each encounter.

\section{Assessing Treg percentage and suppressive function in the peripheral blood}

Peripheral blood was drawn 1 month before the first Treg infusion, immediately before each infusion, the day after each infusion, every 2 weeks during each round of infusions, and monthly after each round. The percentage of $\mathrm{CD} 4^{+} \mathrm{CD} 25^{+}$ $\mathrm{FOXP}^{+}$Tregs within the total $\mathrm{CD} 4^{+}$population was assessed by flow cytometry. ${ }^{8}$ Treg suppressive function on the 
Table Patient characteristics

\begin{tabular}{|c|c|c|c|}
\hline Patient No. & 1 & 2 & 3 \\
\hline Age (yr) & 47 & 46 & 56 \\
\hline Sex & Male & Male & Female \\
\hline Initial weight (kg) & 92 & 77 & 79 \\
\hline Site of symptom onset & Arm & Bulbar & Leg \\
\hline Time from symptom onset to diagnosis (mo) & 7 & 18 & 12 \\
\hline Time from symptom onset to the 1st Treg infusion (mo) & 14 & 24 & 38 \\
\hline Riluzole use at study entry & Yes & Yes & Yes \\
\hline Noninvasive ventilation use at study entry & No & Yes & No \\
\hline ALSFRS-R just before the 1st Treg infusion & 44 & 36 & 41 \\
\hline AALS just before the 1st Treg infusion & 50 & 65 & 68 \\
\hline FVC (L) just before the 1st Treg infusion & 5.25 & 2.84 & 2.24 \\
\hline FVC (\% predicted) just before the 1st Treg infusion & 92 & 56 & 77 \\
\hline MIP $\left(\mathrm{cm} \mathrm{H}_{2} \mathrm{O}\right)$ just before the 1st Treg infusion & 120 & 50 & 100 \\
\hline
\end{tabular}

Abbreviations: AALS = Appel Amyotrophic Lateral Sclerosis Rating Scale; ALSFRS-R = revised Amyotrophic Lateral Sclerosis Functional Rating Scale; FVC = forced vital capacity; MIP = maximal inspiratory pressure.

proliferation of autologous responder $\mathrm{T}$ lymphocytes was assessed by $\left[{ }^{3} \mathrm{H}\right]$-thymidine incorporation. ${ }^{8}$

\section{Statistical analysis}

Correlation between changes in the AALS and Treg suppressive function was determined by Spearman correlation using GraphPad Prism 7 software and depicted by Spearman rho $(\rho)$. Two-tailed $p$ values $<0.05$ were considered statistically significant. Data collected between the first and fifth Treg infusions were compared with values from the day of the first infusion. Data collected after the fifth Treg infusion were compared with the values from the day of the fifth infusion.

\section{Data availability}

Individual deidentified patient data not published within the article including clinical evaluations and Treg percentage and suppressive function results will be shared by request from any qualified investigator.

\section{Results}

\section{Safety}

No infusion-related adverse events or clinically significant changes in safety laboratories or electrocardiogram findings were observed. All patients noted dramatic increases in the frequency, intensity, and distribution of fasciculations during each round of infusions. Fasciculations were noted within a few minutes to a few days after each Treg infusion and lasting from days to more than 1 month after the completion of each round of infusions. Patient 1 experienced increased muscle cramps in his legs from weeks 2-6, 2 falls on weeks 17 and 23, and an episode of pharyngitis on week 10. Patient 2 underwent placement of a percutaneous endoscopic gastrostomy tube on week 9. He developed aspiration pneumonia on week 19, and his IL-2 injections were temporarily suspended until week 23. His progressive dysphagia and episode of aspiration pneumonia were likely due to his bulbar ALS. Patient 2 dropped out of the study on week 50 because of his progressive disease and was placed in hospice care. He died on week 51 because of respiratory failure secondary to ALS. Patient 3 developed 2 suspected gastrointestinal infections and an upper respiratory infection between weeks 24 and 29. She reported mild dyspnea on exertion beginning on week 48 .

\section{Treg percentage and suppressive function increased during infusions}

In all patients, Treg percentage (figure $1, \mathrm{~A}-\mathrm{C}$ ) and suppressive function (figure 1, D-F) increased during the first round of infusions, declined between each round of infusions, and increased again during the second round.

\section{Enhanced Treg suppressive function correlated with slowing of functional decline}

In all patients, the rate of decline of the ALSFRS-R and AALS slowed for 2 months during the first round of infusions, accelerated between each round of infusions, and slowed again over 4 months during the second round (figure 2, A-C). Spearman correlation showed that increased Treg suppressive function correlated with slowing of disease progression per the AALS for each patient (figure 2, D-F; $\rho=-0.60, p=0.003$ in patient $1 ; \rho=-0.71, p=0.0026$ in patient 2 ; and $\rho=-0.54$, $p=0.016$ in patient 3$)$. The larger the increase in Treg 

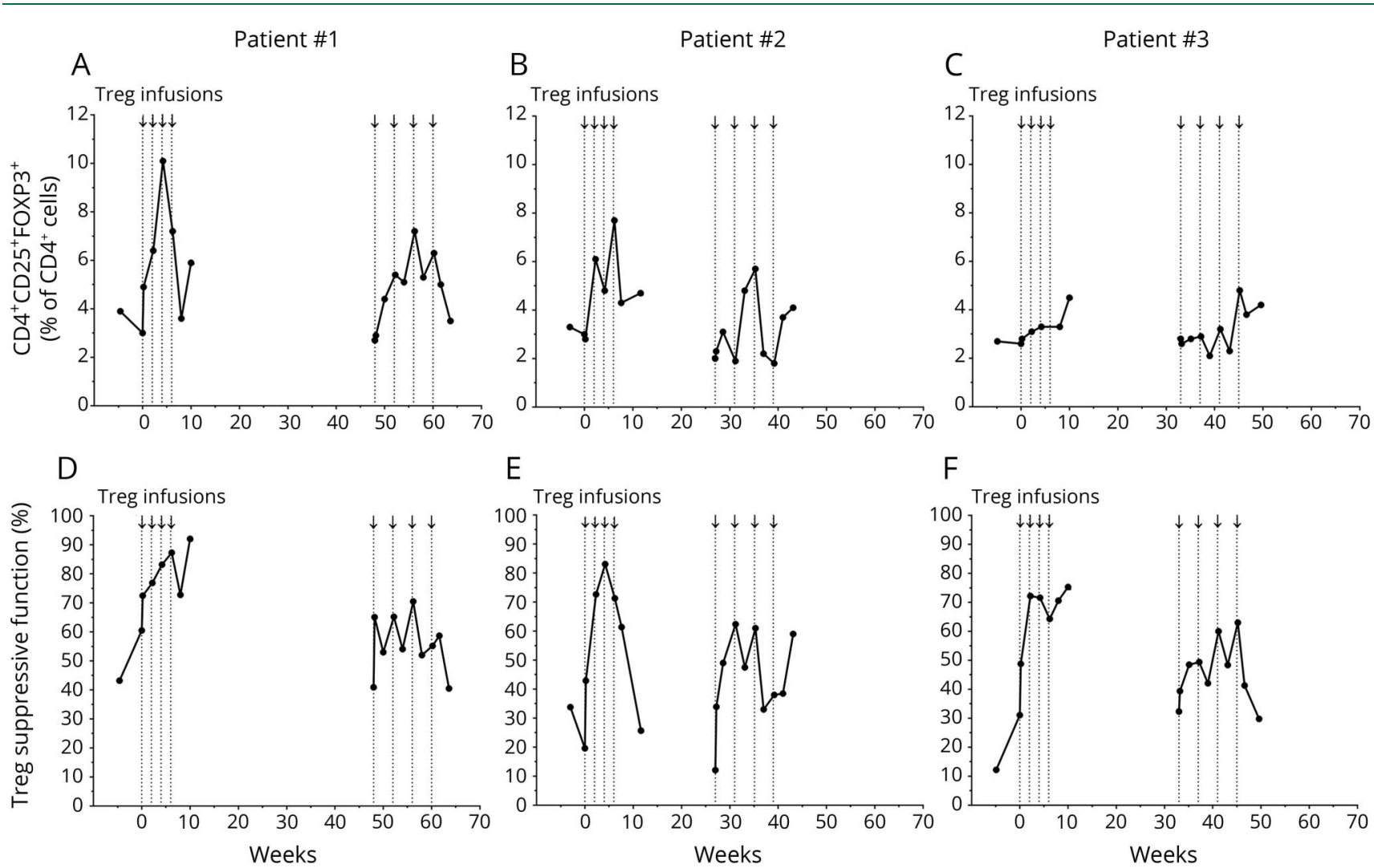

Arrows and vertical dotted lines represent Treg infusions. The 1st Treg infusion was administered on week 0 and then every 2 weeks for a total of 4 infusions. The 5th Treg infusion was administered in each patient on weeks 48,27 , and 33 , respectively, and then every 4 weeks for a total of 4 infusions. The percentage of $\mathrm{CD}^{+} \mathrm{CD}_{25} 5^{+} \mathrm{FOXP3}^{+}$Tregs within the total $\mathrm{CD} 4^{+}$cell population is shown for patient 1 (A), patient 2 (B), and patient 3 (C). Treg percentages are shown at baseline (weeks 4.6, 3.0, and 4.9 in each patient, respectively), the days of the $1 \mathrm{st}$ and 5 th Treg infusions, the day after each Treg infusion, every 2 weeks during each round of infusions, and 1 month after each round. The data point collected the day after the 4th Treg infusion (week 6) in patient 3 was not determined because of a flow staining error. Treg suppressive function is shown on the same time points as the Treg percentages for patient $1(\mathrm{D})$, patient $2(\mathrm{E})$, and patient $3(\mathrm{~F})$.

suppressive function, the smaller the decline in the AALS at the next clinical evaluation.

\section{MIPs stabilized during infusions}

In all patients, the FVC remained relatively unchanged during the Treg infusions and between each round (figure 3, A-C). In patients 1 and 3, the MIPs were stable during the first round of infusions and deteriorated between each round. The MIPs again stabilized during the second round. Patient 2 was treated with noninvasive ventilation before enrollment and continued treatment throughout the study. In patient 2, MIPs were low, but remained relatively stable during each round of infusions and between each round (figure 3, D-F).

\section{Discussion}

Three patients with ALS were infused with autologous expanded Tregs with concomitant subcutaneous IL-2 injections at early and later stages of disease. Tregs were also infused at a later stage of disease to determine whether the infusions remained safe and the beneficial effects on disease progression could be extended by increasing the dosing interval. Treg infusions were safe and well tolerated regardless of the burden of disease. Treg suppressive function correlated with changes in the AALS; the greater the improvement in Treg suppressive function, the slower the rate of clinical progression. This correlation supports the value of Treg suppressive function as a meaningful indicator of clinical status. In addition, Treg infusions did not adversely affect respiratory function and appeared to stabilize the decline in MIPs in the 2 patients who were not being treated with noninvasive ventilation.

In a previous pilot study, low-dose IL-2 administered subcutaneously for 1 year in 5 patients with ALS was safe and tolerable, but did not appear to alter the clinical course or increase endogenous Treg numbers, likely related to impaired endogenous Treg responsiveness to IL-2 (unpublished results). In the present study, subcutaneous injections of lowdose IL-2 were administered to stabilize the infused expanded Tregs. During infusions in all patients, several data points were observed in which IL-2 could have enhanced the proliferation and function of infused Tregs. However, IL-2 was 
Figure 2 Disease progression slowed during each round of Treg infusions and correlated with increased Treg suppressive function

A. Patient \#1

A.a

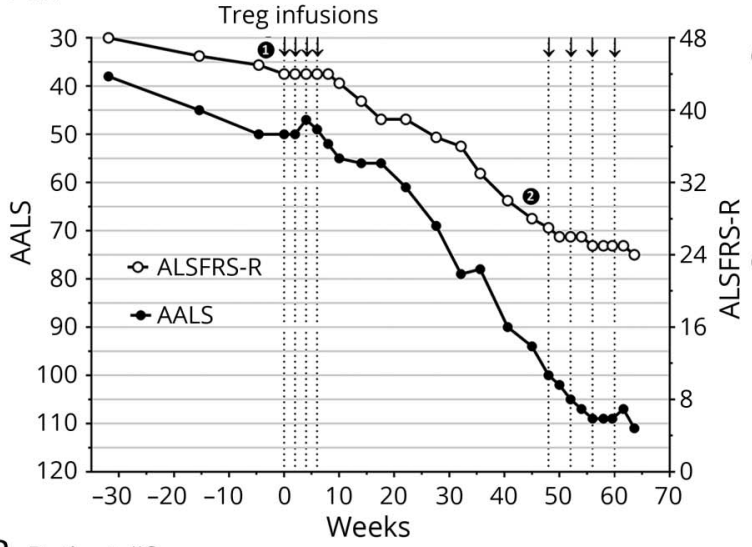

B. Patient \#2

B.a

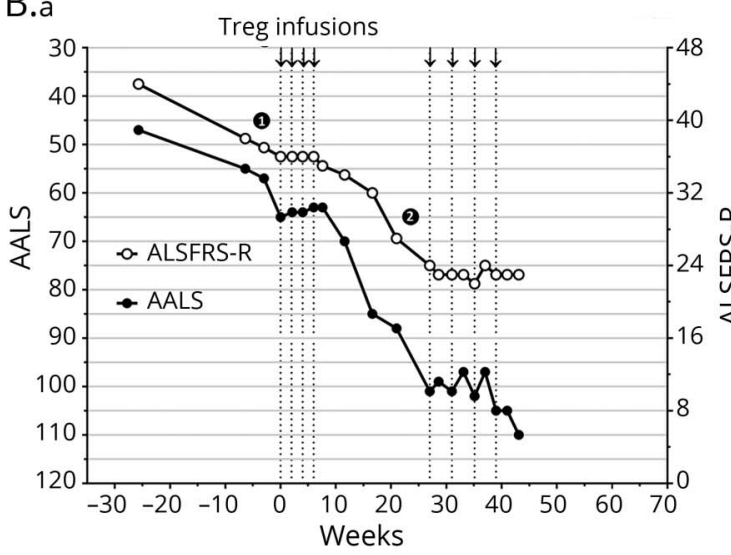

C. Patient \#3

C.a

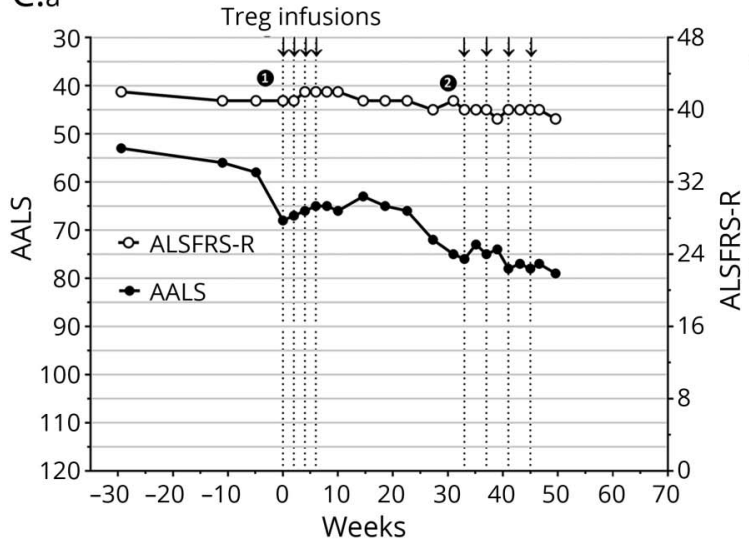

A.b

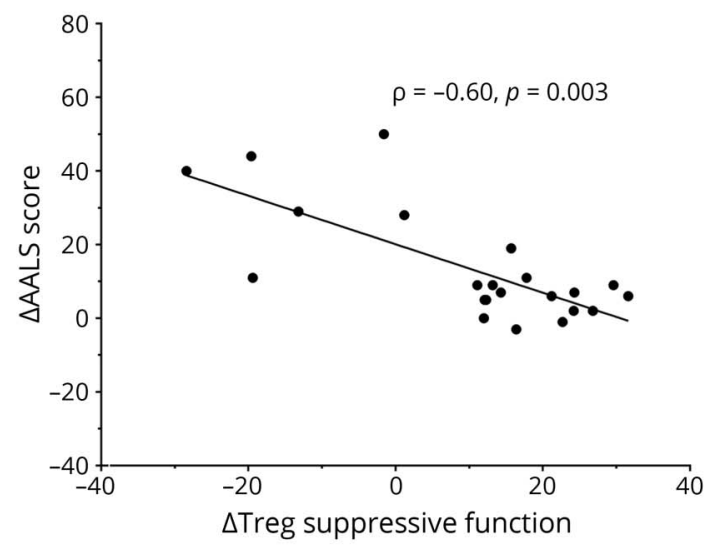

B.b

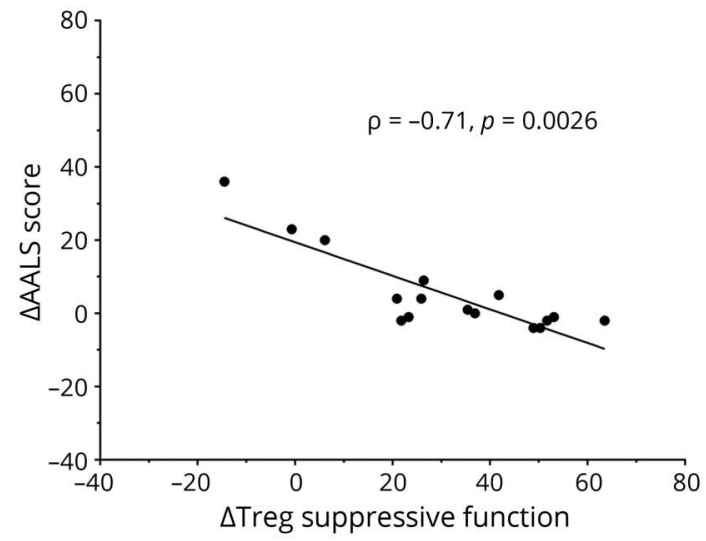

C.b

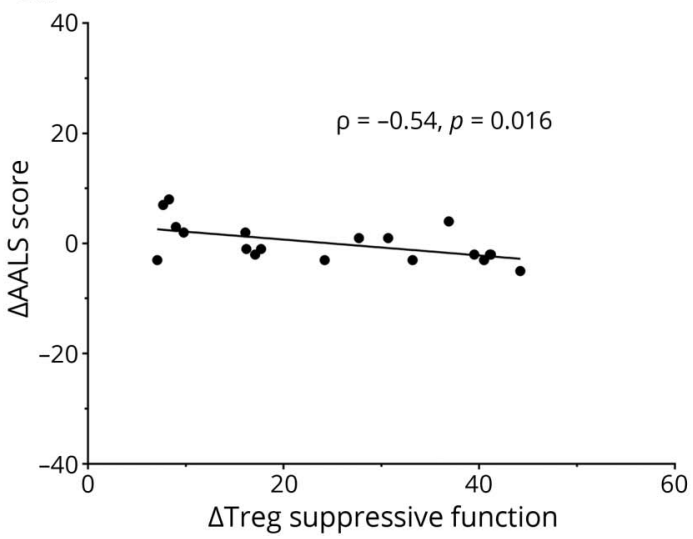

Arrows and vertical dotted lines represent Treg infusions. Clinical progression is depicted by the ALSFRS-R (white points) and AALS (black points) stages of the disease for patient 1 (A.a), patient 2 (B.a), and patient 3 (C.a). Clinical progression lines during each round of Treg infusions are enlarged in side panels for the early (1) and later (2) stages of disease. Correlation between changes in the AALS and Treg suppressive function is shown for patient 1 (A.b), patient 2 (B.b), and patient 3 (C.b). Lines represent the best fit as determined by linear regression analysis. Data were analyzed by Spearman correlation, and $p$ values $<0.05$ were considered statistically significant. AALS = Appel Amyotrophic Lateral Sclerosis Rating Scale; ALSFRS-R = revised Amyotrophic Lateral Sclerosis Functional Rating Scale.

not of critical value in the interim between each round when Treg percentage and suppressive function and clinical status deteriorated.
Common to all patients was the perceived increase in fasciculations. The rapid onset of fasciculations suggests a peripheral action in the lower motor neuron possibly mediated by 

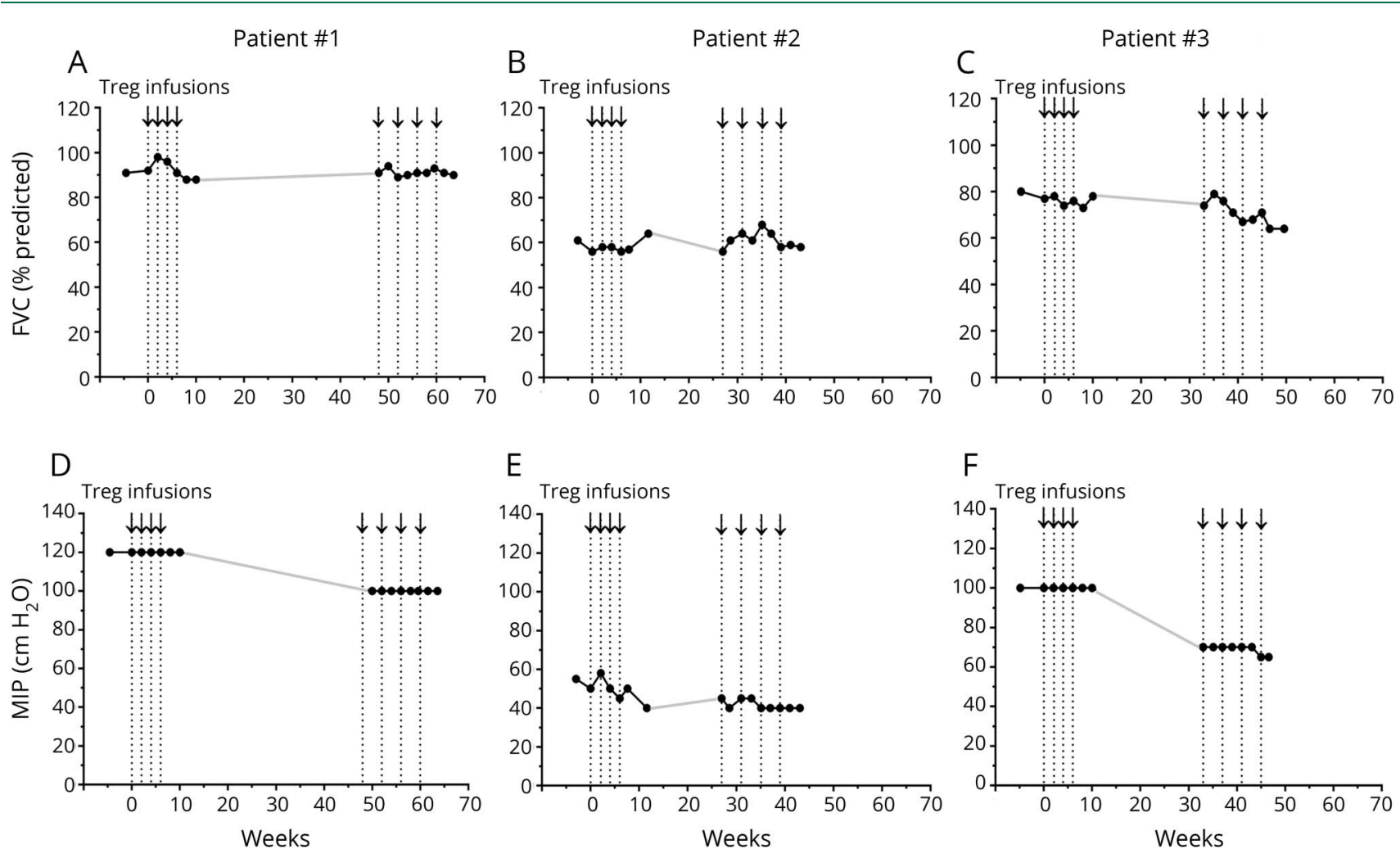

Arrows and vertical dotted lines represent Treg infusions. FVC measurements are represented as \% predicted values for patient 1 (A), patient 2 (B), and patient 3 (C). Measurements are shown at baseline (weeks 4.6, 3.0, and 4.9 in each patient, respectively), immediately before each Treg infusion, every 2 weeks during each round of infusions, and 1 month after each round. MIP measurements are shown in $\mathrm{cm} \mathrm{H}_{2} \mathrm{O}$ for patient 1 (D), patient 2 (E), and patient 3 (F). MIPs are shown at the same time points as FVC measurements. The MIP values were erroneously not determined for patient 1 immediately before the 5 th Treg infusion, and for patient 3,1 month after the second round of infusions. The solid gray line connects the points between each round of infusions (A-F). FVC = forced vital capacity; MIP = maximal inspiratory pressure.

immune modulation of ectopic axonal firing. In the earlier IL2-alone pilot study, increased fasciculations were not observed, suggesting that the infused Tregs directly or indirectly caused the fasciculations in this study. In addition, common to all patients was the occurrence of infections during the study: pharyngitis in patient 1 , aspiration pneumonia in patient 2 , and gastrointestinal and upper respiratory infections in patient 3 . A potential increased risk of infections with Treg and IL-2 treatment is concerning and requires further study in a larger number of patients with ALS.

Although this study lacked blinding and placebo controls, slowing of disease progression was observed during the initial infusions at an early stage of disease and the subsequent 4 monthly infusions at a later stage of disease. Administering the ALSFRS-R to the patients during the initial infusions every 2 weeks enhances the likelihood of a placebo effect. However, we have not observed stabilization of the AALS in previous studies of subcutaneous IL-2 injections (unpublished) or infusions of allogeneic hematopoietic stem cells. ${ }^{11}$ Furthermore, the increased Treg suppressive function, which correlated with the clinical state, and the observed stabilization of MIPs were not likely to have been influenced by a placebo effect. Increased clinical progression rates were observed between each round of infusions, but it was not clear whether the progression was related to the cessation of Treg infusions or would have occurred spontaneously. More pertinent is the observation that subsequent Treg infusions were beneficial at later stages of disease with increased disease burden and rate of progression. Circulating functional Tregs may slow disease progression by suppressing peripheral proinflammatory monocytes/macrophages and responder $\mathrm{T}$ lymphocytes, as well as entering the CNS and suppressing activated microglia. Defining peripheral and central actions of Tregs merits further investigation.

The results from this study support the need for a phase 2, randomized, placebo-controlled trial over a longer period to test the clinical efficacy, safety, and tolerability of different doses of Tregs in a larger number of patients with ALS. The goal of future studies is to determine whether optimized doses of Tregs infused at regular intervals prolong slowed progression and minimize the more rapid progression associated with cessation of Treg infusions.

\section{Author contributions}

Jason R. Thonhoff: study concept and design; acquisition, analysis and interpretation of data; and drafting of the 
manuscript. David R. Beers: study concept and design; acquisition, analysis and interpretation of data; and critical revision of the manuscript. Weihua Zhao: acquisition, analysis and interpretation of data and critical revision of the manuscript. Milvia Pleitez: study concept and design and acquisition, analysis, and interpretation of data. Ericka P. Simpson, James D. Berry, and Merit E. Cudkowicz: study concept and design and critical revision of the manuscript. Stanley H. Appel: study concept and design, study supervision, acquisition of data, analysis and interpretation of data, and critical revision of the manuscript.

\section{Acknowledgment}

The authors dedicate this article to their friend and colleague Jenny S. Henkel, who made considerable contributions to the development of this project through her research. They are grateful to Dan Neal of the University of Florida for his assistance in the statistical analyses. They also appreciate the assistance of Luis Lay, Della Brown, Shixiang Wen, Douglas Casey, Jinghong Wang, Joanna Espinosa, and Yuanfang Liu of the Houston Methodist Neurological Institute and Annette DeMattos and Liz Simpson of the Neurological Clinical Research Institute, Massachusetts General Hospital. They are also grateful to the Stem Cell Transplantation and Cellular Therapy facility at M.D. Anderson Cancer Center for manufacturing the Tregs.

\section{Study funding}

ALS Finding a Cure ${ }^{\circledast}$ and the ALSA.

\section{Disclosure}

J.R. Thonhoff is supported by the Houston Methodist Clinician Scientist Recruitment and Retention Program. D.R. Beers, W. Zhao, and M. Pleitez report no disclosures. E.P. Simpson receives publishing royalties from McGraw-Hill and was a speaker for Alexion Pharmaceuticals. J.D. Berry served on the scientific advisory board of MT Pharma, Denali Therapeutics, and Orion Corporation; received travel funding from ALSA, MDA, and ALS ONE; is a consultant to Denali Therapeutics; has received fellowship support from Voyager Therapeutics and research funding from Cytokinetics, Neuraltus, Amylyx Pharmaceuticals, Brainstorm Cell Therapeutics, NIH/NINDS,
MDA, ALS Finding a Cure, ALSA, and ALS ONE; holds a patent for microRNAs in neurodegenerative disorders; and his spouse is on the editorial board of Neuropsychopharmacology. M. E. Cudkowicz serves on the scientific advisory board of Cytokinetics, SAB, Lilly and DSMB; is on the editorial board of Neurotherapeutics and JAMA Neurology; holds a patent for metabolomics in ALS; receives publishing royalties from UpToDate; serves as a consultant to Biogen Idec, Immunity Pharma, Biogen, AveXis, Revalesio, Mitsubishi Tanabe Pharma, Avanir, MDA, Cytokinetics, Lilly, Karyopharm, and Orion; and received research support from the NINDS, ALSA, and ALS Finding a Cure Foundation. S.H. Appel serves as a scientific consultant to Mitsubishi Tanabe Pharma, Neuraltus, and UCB Biopharma; received speaker honoraria from and served on the speaker's bureau of Avanir; received research support from the ALSA, ALS Finding a Cure, and Lee Rizzuto Foundation; and served as an expert consultant in ALS case. Full disclosure form information provided by the authors is available with the full text of this article at Neurology.org/NN.

Received February 6, 2018. Accepted in final form April 11, 2018.

\section{References}

1. Sakaguchi S. Naturally arising Foxp3-expressing CD25+CD4+ regulatory $\mathrm{T}$ cells in immunological tolerance to self and non-self. Nat Immunol 2005;6:345-352.

2. Viglietta V, Baecher-Allan C, Weiner HL, Hafler DA. Loss of functional suppression by CD4+CD25+ regulatory $\mathrm{T}$ cells in patients with multiple sclerosis. J Exp Med 2004;199:971-979.

3. Dejaco C, Duftner C, Grubeck-Loebenstein B, Schirmer M. Imbalance of regulatory $\mathrm{T}$ cells in human autoimmune diseases. Immunology 2006;117:289-300.

4. Bluestone JA, Buckner JH, Fitch $\mathrm{M}$, et al. Type 1 diabetes immunotherapy using polyclonal regulatory T cells. Sci Transl Med 2015;7:315ra189.

5. Beers D, Henkel JS, Zhao W, et al. Endogenous regulatory T lymphocytes ameliorate amyotrophic lateral sclerosis in mice and correlate with disease progression in subjects with amyotrophic lateral sclerosis. Brain 2011;134:1293-1314.

6. Zhao W, Beers DR, Liao B, Henkel JS, Appel SH. Regulatory T lymphocytes from ALS mice suppress microglia and effector T lymphocytes through different cytokinemediated mechanisms. Neurobiol Dis 2012;48:418-428.

7. Henkel JS, Beers DR, Wen S, et al. Regulatory T-lymphocytes mediate amyotrophic lateral sclerosis progression and survival. EMBO Mol Med 2013;5:64-79.

8. Beers DR, Zhao W, Wang J, et al. ALS patients' regulatory T lymphocytes are dysfunctional, and correlate with disease progression rate and severity. J Clin Invest Insight 2017;2:e89530.

9. Alsuliman A, Appel SH, Beers DR, et al. A robust, good manufacturing practicecompliant, clinical-scale procedure to generate regulatory $\mathrm{T}$ cells from patients with amyotrophic lateral sclerosis for adoptive cell therapy. Cytotherapy 2016;18: 1312-1324.

10. Haverkamp LJ, Appel V, Appel SH. Natural history of amyotrophic lateral sclerosis in a database population: validation of a scoring system and a model for survival prediction. Brain 1995;118:707-719.

11. Appel SH, Engelhardt JI, Henkel JS, et al. Hematopoietic stem cell transplantation in patients with sporadic amyotrophic lateral sclerosis. Neurology 2008;71:1326-1334. 


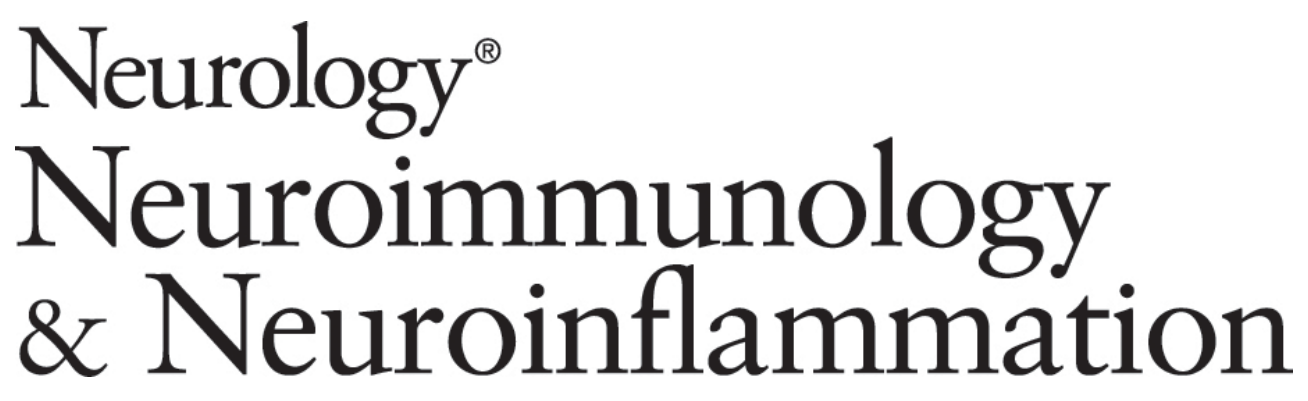

Expanded autologous regulatory T-lymphocyte infusions in ALS: A phase I, first-in-human study

Jason R. Thonhoff, David R. Beers, Weihua Zhao, et al.

Neurol Neuroimmunol Neuroinflamm 2018;5;

DOI 10.1212/NXI.0000000000000465

This information is current as of May 18, 2018

Neurol Neuroimmunol Neuroinflamm is an official journal of the American Academy of Neurology.

Published since April 2014, it is an open-access, online-only, continuous publication journal. Copyright

Copyright $\odot 2018$ The Author(s). Published by Wolters Kluwer Health, Inc. on behalf of the American

Academy of Neurology.. All rights reserved. Online ISSN: 2332-7812.

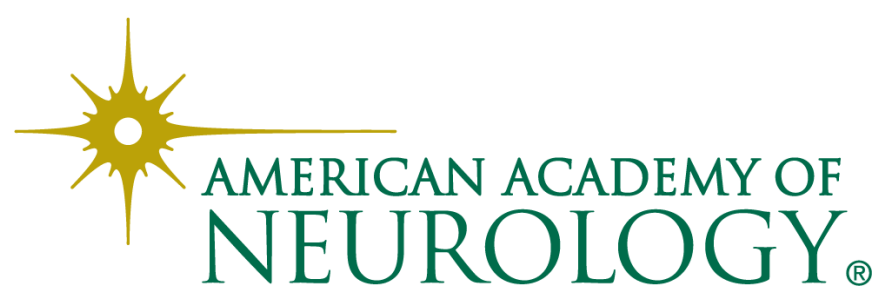




\section{Updated Information \& Services}

References

Citations

Subspecialty Collections

Permissions \& Licensing

Reprints including high resolution figures, can be found at: http://nn.neurology.org/content/5/4/e465.full.html

This article cites 11 articles, 3 of which you can access for free at: http://nn.neurology.org/content/5/4/e465.full.html\#\#ref-list-1

This article has been cited by 5 HighWire-hosted articles: http://nn.neurology.org/content/5/4/e465.full.html\#\#otherarticles

This article, along with others on similar topics, appears in the following collection(s):

\section{All Clinical trials}

http://nn.neurology.org//cgi/collection/all_clinical_trials All Immunology http://nn.neurology.org//cgi/collection/all_immunology Amyotrophic lateral sclerosis http://nn.neurology.org//cgi/collection/amyotrophic_lateral_sclerosis_ Class IV http://nn.neurology.org//cgi/collection/class_iv

Information about reproducing this article in parts (figures,tables) or in its entirety can be found online at:

http://nn.neurology.org/misc/about.xhtml\#permissions

Information about ordering reprints can be found online: http://nn.neurology.org/misc/addir.xhtml\#reprintsus

Neurol Neuroimmunol Neuroinflamm is an official journal of the American Academy of Neurology.

Published since April 2014, it is an open-access, online-only, continuous publication journal. Copyright

Copyright $\odot 2018$ The Author(s). Published by Wolters Kluwer Health, Inc. on behalf of the American Academy of Neurology.. All rights reserved. Online ISSN: 2332-7812.

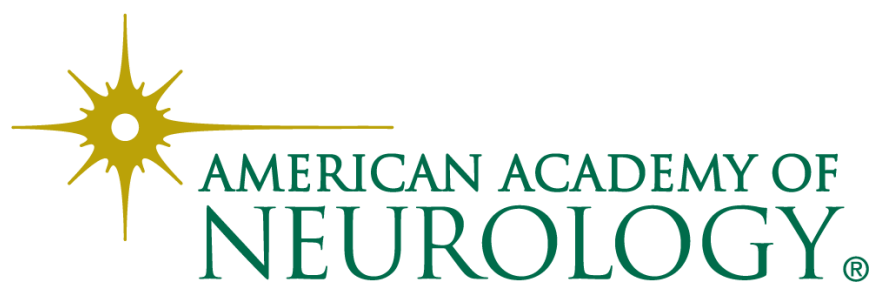

